\title{
BMJ Open Work and non-work stressors, psychological distress and obesity: evidence from a 14-year study on Canadian workers
}

\author{
Alain Marchand, ${ }^{1}$ Nancy Beauregard, ${ }^{1}$ Marie-Eve Blanc ${ }^{2}$
}

To cite: Marchand A, Beauregard N, Blanc M-E. Work and non-work stressors, psychological distress and obesity: evidence from a 14-year study on Canadian workers. BMJ Open 2015;5:e006285. doi:10.1136/bmjopen-2014006285

- Prepublication history for this paper is available online. To view these files please visit the journal online (http://dx.doi.org/10.1136/ bmjopen-2014-006285).

Received 8 August 2014 Revised 11 February 2015 Accepted 12 February 2015

CrossMark

For numbered affiliations see end of article.

\section{Correspondence to} Dr Alain Marchand; alain.marchand@umontreal. ca

\section{ABSTRACT}

Objective: This study aimed to evaluate the contribution of work, non-work and individual factors to obesity with regard to gender-related differences, and to clarify the mediating role that psychological distress plays in these dynamics in Canada from 1994 to 2008 using the Canadian National Population Health Survey (NPHS).

Design: Longitudinal.

Settings: The NPHS is a randomised longitudinal cohort study with biennial interviews of the Canadian adult population from 18 to 64 .

Participants: 5925 non-obese workers in cycle 1 (49\% were women).

Measurements: Obesity was measured using the body mass index (BMI), with a threshold of BMI $>30 \mathrm{~kg} / \mathrm{m}^{2}$. BMI was corrected in accordance with the recommendations of Connor Gorber et al to adjust for gender bias in responses.

Results: Of the work characteristics evaluated, only decision authority was associated with obesity for women but not for men. Living as a couple, childrelated strains, psychotropic drug use, hypertension, being physically inactive and low psychological distress were obesity risk factors but were not moderated by gender. Overall, psychological distress did not mediate the associations that work factors have on obesity.

Conclusions: Our study suggests that men and women differ little in the extent to which work, nonwork and individual factors predict obesity. However, for women, the level of decision authority is associated with a lower obesity risk. In addition, psychological distress did not mediate the contribution of work factors and actually seems, contrary to expectations, to decrease the obesity risk when work, non-work and individual factors are taken into account.

\section{INTRODUCTION}

Obesity develops primarily from imbalance between excessive consumption of highcalorie foods and declines in physical activity. Genetic factors do not appear to play a prominent role, as genetic predispositions
Strengths and limitations of this study

- This 14-year study is representative of the Canadian workforce aged from 18 to 64 years.

- Our study is using repeated measures multilevel logistical regression models that were gender stratified.

- The body mass index measure we used is derived from self-reported data, although it has been corrected to minimise gender response bias.

- We did not control for high levels of exposure to physical and chemical risks.

- The measure we used for physical activity was based solely on the duration that respondents assigned to it for the 3 months preceding the survey.

may be countered by a health-conscious lifestyle. ${ }^{1}$ The study of social determinants of obesity is a promising avenue, because longitudinal studies tend to support the existence of causal relationships between living environments (eg, both work and non-work such as family, networks, community), obesity and mental health problems. ${ }^{2}{ }^{3}$ However, little is known about the concomitant associations of work and non-work risk factors on obesity and mental health problems among workers.

This article aims to rectify this by analysing representative longitudinal data for the Canadian workforce population over a 14-year period.

\section{Workplace factors and obesity}

Workplace factors that contributed directly to obesity are limited in number, ${ }^{45}$ and most longitudinal studies focus on weight change than on body mass index (BMI). ${ }^{6}$ Overall, only long working hours showed a consistent contribution to higher risks of obesity over time. ${ }^{7}$ However, several longitudinal studies have tested the demand-control (DC) model, $^{8}$ the demand-control-support (DCS) $\operatorname{model}^{9}$ and 
the effort-reward-imbalance (ERI) model. ${ }^{10}$ Under the DC model, workplace demands were associated with weight gains or increases in BMI levels ${ }^{11}{ }^{12}$ in women and men. ${ }^{11}$ High physical demand levels were positively associated with the highest BMI levels among men ${ }^{13}$ and greater weight gains among women. ${ }^{14}$ Psychological demands were positively associated with weight gains among female nurses over a 6 -year period, ${ }^{15}$ and presented a U-shaped pattern in a male cohort study. ${ }^{16}$

Low workplace control (a combination of decision authority and skill utilisation) was positively associated with obesity ${ }^{17} 18$ and weight gains in men ${ }^{11}$ and women ${ }^{15}$ who were already overweight. In recent studies that did not use gender-based models, low workplace control was not significant. ${ }^{12} 19$ As for social support in the workplace, only one study found low levels of support among men to be associated with increases in BMI and abdominal obesity over time. ${ }^{20}$

Job strain (low control, high psychological demands) was found to be positively associated with increases in BMI among middle-aged (40-59 years) women across a 5-year period, ${ }^{21}$ while only men with high BMI $\left(>27 \mathrm{~kg} / \mathrm{m}^{2}\right)$ gained additional weight as a result of job strain, whereas men with lower BMI experienced weight loss. ${ }^{11} \mathrm{~A}$ meta-analysis of 13 European cohort studies revealed that job strain led just as often to weight loss among underweight employees as to weight gain among obese employees. ${ }^{12}$ Isostrain (low control and low social support at work, high psychological demands) yielded similar results: men with more isostrain episodes were at greater risk for becoming obese, ${ }^{20}$ while it was not significant in women.

Studies of the role of the ERI model in obesity risk yielded mixed results. Although one study showed that imbalance between effort and reward was positively associated with increases in BMI over a 10 -year period, ${ }^{18}$ another, based on a small sample $(\mathrm{N}=72)$ and conducted over a 2-year period, showed that ERI was a poor BMI predictor. ${ }^{17}$ Similarly, job insecurity has not only been associated with weight increases in men who were already obese, but also with weight losses among low-BMI workers. ${ }^{16}$

Regarding work contract, overtime was positively associated with weight increases of more than $15 \mathrm{~kg}$ over a 10 -year period, ${ }^{22}$ as was overtime exceeding $6 \mathrm{~h} /$ week among men. ${ }^{14}$ Nevertheless, reducing overtime hours also seemed to give rise to substantial weight gain among men. ${ }^{14}$ Night work, moreover, was associated with significant weight gains among women. ${ }^{23}$ Weekend and fixed work schedules also seemed to favour BMI increases. ${ }^{24}$

\section{Non-work factors and worker obesity}

Few occupational studies have examined the role of non-work factors in relation to obesity. As far as the family is concerned, marital status leads to mixed results. Being single is not associated with the risk of being obese either among men or women,${ }^{25}$ but rather with a decline in BMI over time, ${ }^{24}$ whereas living as a couple may ${ }^{21}$ or may not ${ }^{16}$ explain changes in BMI. Given that family and couple-related strains do not seem to be directly associated with weight change over time among either men or women ${ }^{19}$ work-family conflicts are thought to explain weight gain among women. ${ }^{22}$ As for the social network, men are at lower risk for obesity when time spent with friends is irregular, whereas among women low satisfaction with social networks is associated with an increase in obesity risk. ${ }^{25}$ However, stress among friends is not associated with weight change among either men or women. ${ }^{19}$

Overall, very few studies have tested work and non-work factors at the same time,${ }^{26}$ which would have made it possible to state with more assurance which work factors matter above and beyond the relative contribution of non-work factors to obesity.

\section{Individual factors and worker obesity}

Two longitudinal studies that tested gender differences have found female to be associated with a rise in BMI over time. ${ }^{13}{ }^{24}$ Still, these two studies suffered from major limitations: in one sample, women constituted only a small percentage $(14 \%),{ }^{24}$ and in the other sample manual occupations and low educational levels were overrepresented $\left(73.5 \%\right.$ and $86.5 \%$, respectively) ${ }^{13}$ Age is another factor that leads to ambiguous results: some studies have shown a positive relationship between age and $\mathrm{BMI} ;{ }^{13}$ others have reported opposite results. ${ }^{16}{ }^{24}$ Results on educational level were also mixed. Low educational levels have been positively associated with high BMI values for both genders; ${ }^{21}{ }^{27}$ age, however, moderates the relationship. ${ }^{27}$ In another study, low educational levels were found to interact with female gender. ${ }^{13}$

As for lifestyle factors, results for high or at-risk alcohol consumption diverged. A combined-gender study found consumption to be not statistically associated with increases in BMI. ${ }^{24}$ Another found it to be positively associated with obesity in men but not statistically significant for women. ${ }^{20}$ Cigarette smoking was also tested and it was either positively associated with increased $\mathrm{BMI}^{24}$ or not statistically significant. ${ }^{13}{ }^{28}$ As for physical activities, one study reported a positive association with obesity in women and men; ${ }^{20}$ a second study showed that regular physical activity was associated with lower BMI; ${ }^{21}$ and a third found no association between physical activity and changes in BMI. ${ }^{13}$

To the best of our knowledge, no longitudinal study of obesity in workers has yet tested individual factors such as personality traits or stressful childhood events. Yet since these factors have already been the subject of obesity studies in the general population, it is relevant to include them in our model. ${ }^{29} 30$ The same is true for chronic diseases such as hypertension and diabetes, which have already been incorporated into studies of work stress and cardiovascular disease in workers. ${ }^{31}$

\section{Towards a comprehensive social aetiology model of worker obesity}

The profile of worker obesity, as it relates to the psychosocial risks of living environments and to individual 
characteristics, is complex. Taking gender into account seems paramount for describing the contribution of work, non-work and individual factors as a whole, but a critical question remains to be dealt with: What specific role does mental health play in the association between obesity and work-related, non-work-related and individual-related risk factors? Mental health actually seems to be proving an important determinant of obesity, given that a cohort study has shown that generalised anxiety predicts weight gain in men. ${ }^{19}$ The Whitehall II study has shown a positive association between mental health problems and the development of obesity over time. ${ }^{32}$ We found only one longitudinal study, performed on a small sample of male workers, that showed a causal relationship between weight gain and the development of mental health problems (ie, anxiety, depression) across time. ${ }^{33}$ Thus, there are increasing evidences that mental health problems could predict obesity and that obesity could also predict mental health problems.

Knowledge gained so far suggests that psychosocial risks arising in work and non-work living environments contribute to the development of mental health problems. ${ }^{26}{ }^{34}$ Moreover, to the best of our knowledge, no study has attempted to validate the mediating role that mental health problems play in the association between work and non-work psychosocial risks and obesity. Clarifying the specific nature of co-occurrences between mental health and obesity, as well as specifying their shared determinants, would seem to be a pivotal factor for further enhancing our understanding.

Relying on a validated multilevel theoretical model of workplace mental health determinants, ${ }^{34} 35$ our study is built around a dynamic analysis of worker health that considers living environment diversity (eg, workplace, family, social networks) and individual characteristics (eg, demography, health status, personality traits, lifestyle, stressful childhood events). Its objective is dual: to investigate the role of determinants related to the work and non-work spheres in predicting obesity (ie, its incidence), paying special attention to gender-based differences among Canadian workers; and to clarify the mediating role that mental health plays in those dynamics.

\section{MATERIALS AND METHODS \\ Data}

Longitudinal data came from the National Population Health Survey (NPHS) of Statistics Canada covering the period between 1994-1995 and 2008-2009. Every 2 years (cycles 1-8), the survey gathered data on a representative sample from the Canadian population that included 17276 individuals (response rate 70.7-92.8\%). In this study, a cohort of workers was selected using two criteria: (1) respondents had to have held a job during the preceding 12 months $(\mathrm{N}=8098)$, and (2) they were not obese in 1994-1995 (cycle 1; N=6215). After adjusting for missing values, the sample included 5925 individuals, of whom 2901 were women and 3024 were men. The sample yielded 28848 BMI observations for the period from 1994 to 2008 .

\section{Measures}

Obesity

Obesity was measured using the BMI, with a threshold of BMI $>30 \mathrm{~kg} / \mathrm{m}^{2}$. BMI was corrected in accordance with the recommendations of Connor Gorber $e t a l^{36}$ to adjust for gender bias in responses. The correction applied for men was BMI (measured) $=-1.08+1.08$ $\times($ BMI self-reported $)$ and for women BMI (measured $)=$ $-0.12+1.05 \times$ (BMI self-reported).

\section{Mental health}

Psychological distress was measured using Kessler's K6 questionnaire $^{37}$ based on the Composite International Diagnostic Interview (6 items). ${ }^{38}$ Respondents were asked to use a five-point Likert-type scale (from 'none of the time' to 'all of the time') to indicate the frequency of the following symptoms during the preceding month: so sad that nothing could cheer you up; nervous; restless or fidgety; hopeless; everything was an effort; worthless. Recent research in social epidemiology has argued for the relevance of considering prepathological mental health states such as psychological distress as a continuum rather than a binary outcome, an operationalisation most often associated with caseness on specific psychopathological disorders. ${ }^{39}{ }^{40}$ Psychological distress was thus treated as a range from 0 to 24 (Cronbach's $\alpha=0.77$ ).

\section{Workplace}

Work factors were measured using questions adapted from the Job Content Questionnaire (JCQ), ${ }^{41}$ including skill utilisation (3 items), decision authority (2 items), psychological demands (2 items), physical demands ( 1 item), social support in the workplace (3 items) and job insecurity (1 item). Measurements of work factors also included the total number of hours worked in the primary job and in other jobs per week, as well as irregular work schedules $(0=$ regular schedule, $1=$ irregular schedule). Skill utilisation, decision authority, psychological and physical demands, social support, job insecurity and working hours per week were used as continuous variables in analyses.

\section{Family and social network}

Non-work factors encompassed family and networkrelated measures. Family variables included marital status ( $1=$ living as couple and $0=$ other), household income classed according to five levels of income sufficiency, parental status according to the presence or absence of children under age 12 ( 1 =present, $0=$ absent), couple-related strains (3 items) and child-related strains (2 items). ${ }^{42}$ Social support outside the workplace was measured using a four-item social support scale, which was then dichotomised ( $0=$ low, $1=$ high $)$. 
Individual characteristics

Individual characteristics were measured by age (in years, as reported for cycle 1$)$; gender $(0=$ men, $1=$ women $)$; educational level (14 levels, highest level attained); locus of control (7 items) ${ }^{43}$ stressful childhood events (7 items) ${ }^{42}$ high-risk alcohol consumption, in line with Canadian gender-based standards for low-risk consumption, derived from the quantity and typical frequency of alcohol consumption; tobacco use (number of cigarettes smoked per day); physical activity (number of sessions $\geq 15$ min during the preceding 3 months); hypertension (diagnosis in the preceding 12 months); diabetes (diagnosis in the preceding 12 months); and use of psychotropic drugs in the preceding 2 days and in the preceding month. All these variables have been associated with obesity and mental health in the past.

\section{Analysis}

The data are structured hierarchically such that measures taken over time (level 1) are nested within individuals (level 2). Repeated-measures multilevel logistical regression models were estimated using MLwiN V.2.27. The analyses were weighted at the individual level taking into account selection probability, non-response rates for each cycle, distribution by gender, age and province of residence as given in the 1996 Canadian population census. To take care of the design effects in the NPHS, SEs were inflated by the square root of the design effects (1.64) at cycle $1 .{ }^{44} 45$ All models were run separately for men and for women. Parameters were estimated by the first-order marginal quasi-likelihood method. Models were estimated hierarchically by introducing independent variables using Baron and Kenny's method in order to evaluate any mediating effect for psychological distress. ${ }^{46}$ Analyses are first carried out on both genders combined, then by gender to examine gender differences in both direction and magnitude of associations. ${ }^{47}$

\section{RESULTS}

Table 1 presents the sample descriptive statistics at cycle 1 .

According to figure 1, obesity among men cumulated from $5.6 \%$ in 1996 (cycle 2) to $14.9 \%$ in 2008 (cycle 8), and among women from $4 \%$ in 1996 to $11.1 \%$ in 2008 .

Table 2 presents the correlation matrix between the study's variables. Of note, all work variables are significantly correlated with psychological distress, which is an indication that psychological distress could therefore

Table 1 Descriptive statistics, National Population Health Survey (cycle 1)

\begin{tabular}{|c|c|c|c|c|}
\hline & \multicolumn{2}{|l|}{ Men } & \multicolumn{2}{|l|}{ Women } \\
\hline & Mean, \% & SD & Mean, \% & SD \\
\hline Psychological distress & 2.93 & 2.87 & 3.52 & 3.23 \\
\hline \multicolumn{5}{|l|}{ Work } \\
\hline Skill utilisation & 7.27 & 2.37 & 6.84 & 2.39 \\
\hline Decision authority & 5.63 & 1.85 & 5.13 & 1.95 \\
\hline Psychological demands & 4.57 & 1.83 & 4.74 & 1.82 \\
\hline Physical demands & 2.21 & 1.35 & 1.93 & 1.29 \\
\hline Social support at work & 8.02 & 2.06 & 7.94 & 2.14 \\
\hline Job insecurity & 1.32 & 1.13 & 1.43 & 1.17 \\
\hline Work schedule (irregular) & 24.10 & & 22.00 & \\
\hline Working hours (total) & 47.32 & 22.47 & 36.92 & 17.78 \\
\hline \multicolumn{5}{|l|}{ Non-work } \\
\hline Marital status (couple) & 66.10 & & 63.40 & \\
\hline Family income & 3.76 & 0.96 & 3.72 & 0.98 \\
\hline Child at home & 33.90 & & 36.50 & \\
\hline Couple-related strains & 0.17 & 0.51 & 0.23 & 0.63 \\
\hline Child-related strains & 0.26 & 0.55 & 0.32 & 0.61 \\
\hline Social support outside work (high) & 82.70 & & 88.70 & \\
\hline \multicolumn{5}{|l|}{ Individual } \\
\hline Gender (women) & 0 & & 100 & \\
\hline Age (in years) & 37.3 & 12.23 & 36.74 & 11.84 \\
\hline Level of education & 6.94 & 3.12 & 7.13 & 2.97 \\
\hline Locus of control & 20.48 & 3.97 & 19.99 & 4.13 \\
\hline Stressful childhood events & 0.76 & 1.07 & 1.00 & 1.24 \\
\hline High-risk alcohol consumption & 9.40 & & 5.40 & \\
\hline Cigarettes & 5.42 & 10.07 & 4.13 & 8.11 \\
\hline Physical activity & 20.66 & 21.64 & 20.14 & 21.11 \\
\hline Hypertension (diagnoses) & 4.10 & & 3.50 & \\
\hline Diabetes (diagnoses) & 1.70 & & 0.60 & \\
\hline Psychotropic drug use & 2.50 & & 6.50 & \\
\hline
\end{tabular}




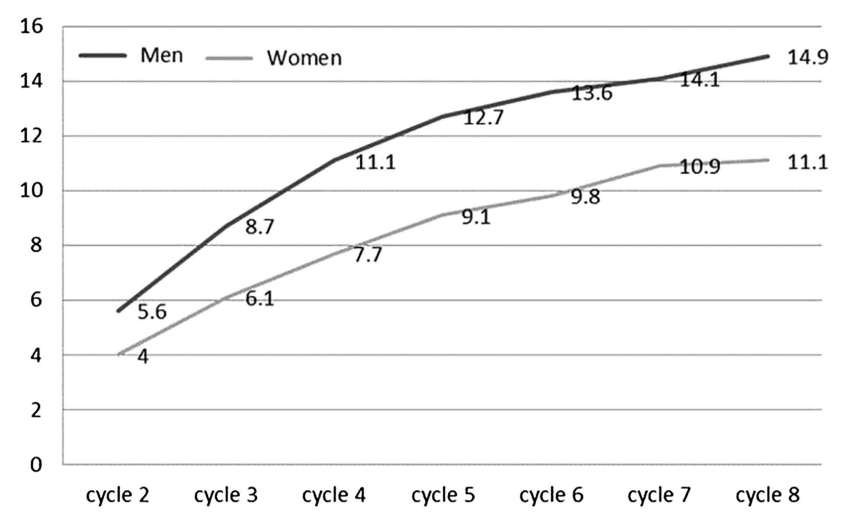

Figure 1 Percentage of body mass index $>30 \mathrm{~kg} / \mathrm{m}^{2}$ over time (National Population Health Survey 1996-2008).

mediate the associations between work factors and obesity.

\section{Men and women considered jointly}

Table 3 presents the multilevel regression results on the pooled men-women sample. Model 1 shows that work factors have no association, although living as a couple is the only non-work factor associated with an increased obesity risk. In terms of individual characteristics, gender (women) and physical activity are significantly associated with a reduced obesity risk over time, while hypertension is associated with an increased obesity risk. In model 2, psychological distress is not significantly associated with obesity, after adjustment for individual characteristics. Psychological distress is also not associated with obesity when only adjusted for gender and age (OR=1.01 95\% CI 0.99 to 1.04 , results not shown). Under model 3, psychological distress is associated with a decreased obesity risk. As for non-work factors, living as a couple is still significant, and child-related strains emerge as an additional risk factor for obesity. Individual characteristics in the preceding models retain their effects in the full model. To these is added psychotropic drug use, which now also becomes a risk factor for obesity risk.

\section{Men}

According to model 1 in table 4 , work is unrelated to the risk of being obese, whereas living as a couple is the only non-work factor associated with an increased obesity risk. With regard to individual characteristics, hypertension is associated with an increased risk of being obese, while physical activity is associated with a decrease in such risk. Model 2 evaluates the link that psychological distress has on obesity after adjusting for individual characteristics. It turns out that psychological distress is not statistically significant, while associations with individual characteristics maintained their significance. Under model 3, psychological distress is still not significant and does not modify the associations with work factors. Living as a couple is still significant, while child-related strains become significant and are associated with an increased obesity risk. The individual characteristics in the preceding models remain significant in the full model.

\section{Women}

Model 1 of table 5 shows that, in terms of work factors, only decision authority is associated with a decreased obesity risk, and non-work factors seemed not to affect obesity risk. Having hypertension almost doubles the chances of being obese, and physical activity is associated with a decreased obesity risk. Model 2 shows that psychological distress is not statistically significant, with the same individual characteristics significant in model 1 , but locus of control also now shows a statistically significant association. Under model 3, psychological distress is still not significant. Decision authority remains significant in the full model. Again, none of the non-work factors is significant. Locus of control is no longer significant, although physical activity and high blood pressure still maintained their associations with obesity.

Overall, as for men and women differences, we conducted an analysis of all the work, non-work and individual-related risk factors in order to detect any interaction effects for gender using the Altman and Bland ${ }^{47}$ method. That analysis indicated that only decision authority has a significant differential effect between men and women $(\mathrm{Z}=2.45, \mathrm{p}<0.01)$.

\section{DISCUSSION}

The objective of this study was to evaluate the contribution of work, non-work and individual factors to obesity with regard to gender-related differences, and to clarify the mediating role that psychological distress plays in these dynamics over a 14-year period. The results of this study add to research on worker obesity, particularly studies that have drawn on broad cohorts, like the Whitehall Study. ${ }^{32}$ First, we have evaluated the relative contribution of the living environments associated with work and non-work (ie, family, social networks), thus acknowledging criticisms that emerged from a systematic review on workers' health. ${ }^{26}$ Second, we have evaluated how psychological distress and obesity were associated when they co-occurred at various points in time by testing for evidence that psychological distress mediated obesity. Finally, we have systematically investigated whether and how obesity dynamics explained differences between men and women in our cohort of workers.

As work is concerned, we found a little contribution of work factors measured in this study on obesity risk when non-work and individual factors are accounted for. Overall, only decision authority was related to obesity and the relationship holds only in women. Higher levels of decision authority were associated with a decreased obesity risk among women. These results differ from those found in the literature, where low decision authority was not statistically significant for obesity in women. ${ }^{19}$ This result helps to go into greater detail than studies 
Table 2 Sample correlation matrix (National Population Health Survey 1994-2010, N=5925)

$\begin{array}{llllllllllllllllllllllllllll}1^{*} & 2 & 3 & 4 & 5 & 6 & 7 & 8 & 9 & 10 & 11 & 12 & 13 & 14 & 15 & 16 & 17 & 18 & 19 & 20 & 21 & 22 & 23 & 24 & 25 & 26\end{array}$

1. Obesity

2. Psychological distress -03

3. Skill utilisation $01-05$

4. Decision authority $\quad 01-11 \quad 29$

5. Psychological demands $\begin{array}{lllll}05 & 11 & 17 & -04\end{array}$

$\begin{array}{lllllll}\text { 6. Physical demands } & -02 & 05 & -21 & -07 & 02\end{array}$

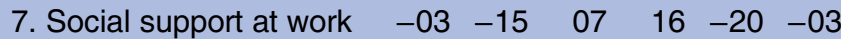

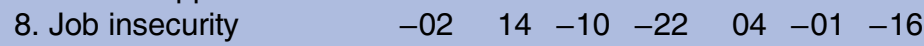

9. Working hours (total) $\quad \begin{array}{lllllllll}04 & 00 & 10 & 10 & 14 & 08 & -01 & -02\end{array}$

10. Work schedule

11. Marital status

12. Family income

13. Child at home

14. Couple-related strains

15. Child-related strains

16. Social support outside

17. Gender (women)

18. Age (in years)

$\begin{array}{llllllll}00 & 03 & -06 & -05 & -01 & 12 & -03 & 05\end{array}$

$\begin{array}{llllllll}05 & -13 & 09 & 11 & 11 & -03 & 01 & -05\end{array}$

$\begin{array}{lllllllllll}08 & -11 & 26 & 13 & 09 & -22 & 01 & -13 & 05 & -05 & 22\end{array}$

$\begin{array}{llllllllllll}00 & -02 & 05 & 01 & 07 & 02 & 00 & -01 & 01 & -02 & 28 & -10\end{array}$

$\begin{array}{lllllllllrlll}01 & 15 & -02 & -04 & 03 & 04 & -08 & 05 & -00 & 00 & 19 & -01 & 08\end{array}$

$\begin{array}{rrrrrrrrrrrrrr}05 & 10 & -02 & -01 & 05 & 05 & -05 & 03 & -01 & 01 & 10 & -01 & 03 & 18\end{array}$

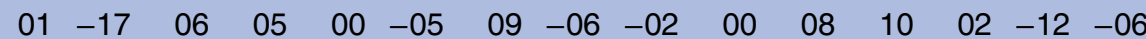

$\begin{array}{rrrrrrrrrrrrrrrrr}06 & -14 & 07 & 13 & -08 & -11 & 03 & -05 & -09 & -06 & 28 & 20 & -25 & 06 & 20 & -05 & -03\end{array}$

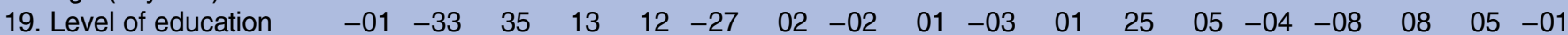

20. Locus of control

21. Childhood events

$\begin{array}{rrrrrrrrrrrrrrrrrrr}-01 & -33 & 35 & 13 & 12 & -27 & 02 & -02 & 01 & -03 & 01 & 25 & 05 & -04 & -08 & 08 & 05 & -01 & \\ 00 & -31 & 16 & 25 & -03 & -09 & 22 & -20 & 05 & -01 & 05 & 04 & 04 & -18 & -16 & 15 & -04 & -05 & 15\end{array}$

22. Alcohol

23. Cigarettes

$\begin{array}{llllllllllllllllllll}02 & 16 & -03 & -06 & 09 & 07 & -11 & -11 & 02 & 03 & -06 & -07 & 02 & 08 & 10 & -03 & 11 & -08 & -05 & -09\end{array}$

24. Physical activity

$\begin{array}{llllllllllllllllllllllll}03 & 04 & 03 & 04 & 01 & 01 & -03 & -00 & 04 & -02 & -03 & 05 & -04 & 01 & 01 & -01 & -07 & -03 & -02 & 02\end{array}$

$\begin{array}{lllllllllllllllllllllllllllllll}-01 & 08 & -09 & -02 & 01 & 13 & -06 & 04 & 08 & 03 & -07 & -13 & -02 & 03 & 09 & -06 & -06 & -03 & -20 & -04 & 14 & 15\end{array}$

25. Hypertension

$\begin{array}{rrrrrrrrrrrrrrrrrrrrrrrrrrrrr}-02 & -04 & 04 & 01 & 01 & -01 & 02 & -05 & -04 & 02 & -04 & 10 & -04 & -04 & -02 & 07 & 01 & -02 & 06 & 08 & 01 & 01 & -11\end{array}$

26. Diabetes (diagnoses)

$\begin{array}{llllllllllllllllllllllllllll}08 & 02 & -03 & 02 & -02 & -02 & -01 & -00 & -04 & -00 & 02 & 03 & -09 & 02 & 07 & -02 & -01 & 25 & -04 & -07 & -00 & -00 & -01 & -01\end{array}$

$\begin{array}{llllllllllllllllllllllllllllll}02 & -00 & -03 & 00 & -03 & -01 & 00 & -01 & 01 & 02 & 00 & -01 & -03 & 00 & 03 & -01 & -03 & 08 & -03 & -01 & -01 & -01 & -02 & 00 & 11\end{array}$

${ }^{*}$ Decimals omitted. All correlations $p<0.01$. 
Table 3 Results of multilevel regression models of obesity (National Population Health Survey 1994-2010, N=5925)

\begin{tabular}{|c|c|c|c|c|c|c|}
\hline & Model 1 & & Model 2 & & Model 3 & \\
\hline Psychological distress & & & 0.98 & $0.95-1.00$ & $0.97^{\star}$ & $0.95-1.00$ \\
\hline \multicolumn{7}{|l|}{ Work } \\
\hline Skill utilisation & 1.00 & $0.97-1.04$ & & & 1.00 & $0.96-1.04$ \\
\hline Decision authority & 0.99 & $0.95-1.03$ & & & 0.99 & $0.95-1.03$ \\
\hline Psychological demands & 1.03 & $0.99-1.08$ & & & 1.04 & $0.99-1.08$ \\
\hline Physical demands & 0.98 & $0.92-1.04$ & & & 0.98 & $0.92-1.05$ \\
\hline Social support at work & 0.98 & $0.94-1.02$ & & & 0.98 & $0.94-1.01$ \\
\hline Job insecurity & 0.95 & $0.89-1.02$ & & & 0.95 & $0.89-1.02$ \\
\hline Work schedule (irregular) & 1.02 & $0.86-1.20$ & & & 1.02 & $0.86-1.21$ \\
\hline Working hours (total) & 1.00 & $0.99-1.00$ & & & 1.00 & $0.99-1.00$ \\
\hline \multicolumn{7}{|l|}{ Non-work } \\
\hline Marital status (couple) & $1.30^{\star \star}$ & $1.07-1.58$ & & & $1.29^{\star \star}$ & $1.06-1.57$ \\
\hline Family income & 1.00 & $0.90-1.10$ & & & 1.00 & $0.90-1.10$ \\
\hline Child at home & 1.01 & $0.85-1.20$ & & & 1.01 & $0.85-1.20$ \\
\hline Couple-related strains & 1.01 & $0.90-1.13$ & & & 1.02 & $0.91-1.14$ \\
\hline Child-related strains & 1.12 & $1.00-1.25$ & & & $1.13^{\star}$ & $1.01-1.26$ \\
\hline Social support outside work (high) & 1.10 & $0.85-1.43$ & & & 1.13 & $0.87-1.47$ \\
\hline \multicolumn{7}{|l|}{ Individual } \\
\hline Gender (women) & $0.60^{\star \star}$ & $0.47-0.75$ & $0.58^{* *}$ & $0.46-0.72$ & $0.60^{\star *}$ & $0.48-0.76$ \\
\hline Age & 1.00 & $0.99-1.01$ & 1.00 & $0.99-1.01$ & 1.00 & $0.99-1.02$ \\
\hline Level of education & 0.99 & $0.95-1.03$ & 0.99 & $0.96-1.03$ & 0.99 & $0.95-1.03$ \\
\hline Locus of control & 1.00 & $0.98-1.01$ & 1.00 & $0.99-1.02$ & 1.00 & $0.98-1.02$ \\
\hline Stressful childhood events & 1.08 & $0.99-1.18$ & $1.10^{*}$ & $1.00-1.20$ & 1.09 & $0.99-1.19$ \\
\hline Hazardous alcohol consumption & 1.13 & $0.86-1.49$ & 1.15 & $0.86-1.54$ & 1.14 & $0.87-1.51$ \\
\hline Cigarettes & 0.99 & $0.98-1.01$ & 0.99 & $0.98-1.01$ & 0.99 & $0.98-1.01$ \\
\hline Physical activity & $0.99^{\star *}$ & $0.99-1.00$ & $0.99^{* *}$ & $0.99-1.00$ & $0.99^{\star *}$ & $0.99-1.00$ \\
\hline Hypertension & $1.56^{\star \star}$ & $1.17-2.07$ & $1.54^{\star *}$ & $1.16-2.04$ & $1.56^{\star \star}$ & $1.17-2.07$ \\
\hline Diabetes & 0.82 & $0.47-1.41$ & 0.83 & $0.48-1.45$ & 0.83 & $0.48-1.44$ \\
\hline Psychotropic drug use & 1.19 & $0.97-1.46$ & 1.22 & $1.00-1.51$ & $1.24^{*}$ & $1.01-1.52$ \\
\hline \multicolumn{7}{|l|}{ Time } \\
\hline Cycle 3 & $4.48^{\star *}$ & $3.60-5.57$ & $4.42^{\star *}$ & $3.57-5.47$ & $4.44^{\star *}$ & $3.57-5.52$ \\
\hline Cycle 4 & $6.08^{\star \star}$ & $4.76-7.77$ & $5.93^{\star *}$ & $4.68-7.51$ & $5.98^{\star \star}$ & $4.68-7.65$ \\
\hline Cycle 5 & $7.28^{\star *}$ & $5.59-9.49$ & $7.22^{\star \star}$ & $5.63-9.26$ & $7.19^{\star \star}$ & $5.52-9.37$ \\
\hline Cycle 6 & $8.48^{\star *}$ & $6.42-11.19$ & $8.50^{* *}$ & $6.55-11.04$ & $8.42^{\star *}$ & $6.38-11.11$ \\
\hline Cycle 7 & $9.78^{\star *}$ & $7.25-13.20$ & $9.83^{\star *}$ & $7.42-13.03$ & $9.71^{\star *}$ & $7.18-13.13$ \\
\hline Cycle 8 & $11.60^{\star \star}$ & $8.49-15.84$ & $11.78^{\star *}$ & $8.78-15.82$ & $11.59^{\star \star}$ & $8.47-15.86$ \\
\hline \multicolumn{7}{|l|}{ Random part } \\
\hline$\sigma^{2}$ Individuals & $3.86^{\star *}$ & $3.14-4.59$ & $3.88^{* *}$ & $3.12-4.64$ & $3.85^{\star \star}$ & $3.13-4.57$ \\
\hline \multicolumn{7}{|l|}{ Goodness-of-fit } \\
\hline$\chi^{2}(d f)$ & $944.86(31)$ & & $832.39(18)$ & & $968.09(32)$ & \\
\hline
\end{tabular}

using models that were not gender stratified ${ }^{13}$ or that relied entirely on male study populations. ${ }^{33}$ This result may be interpreted in the light of improved access to skilled jobs for women in recent decades. ${ }^{48}$ Such jobs typically carry heavier responsibilities (eg, in the quality and quantity of workload). ${ }^{9}$ In England, the trend towards greater obesity between 1997 and 2008 that characterised the professional classes indicated that women holding professional, technical and managerial jobs had the lowest obesity prevalence. ${ }^{49}$ This may be a sign that decision authority makes women more active in their job, requiring them to stay in good shape to cope with challenges from the workplace. Another possible explanation is that high decision authority indicates a higher socioeconomic position, ${ }^{3}{ }^{50}$ and socioeconomic position has been inversely related to obesity. ${ }^{28} 51$
Regarding non-work factors, we found that living in couple and child-related strains are associated with an increased obesity risk, and these relationships are not moderated by gender. As for living in couple, the results are unsupportive of previous studies that do not integrate work and individual factors jointly, ${ }^{16}{ }^{25}$ but give support to a study carried out in the Swedish population. ${ }^{21}$ Overall, this is not consistent with marital status acting as a protective factor for men's health (though not for women) and extends male longevity. ${ }^{52}$ Why living in couple is a risk factor for obesity remains a matter of debate. As for child-related strains, this interesting result had not been investigated by previous research. This also holds true since child-related strains expressed by parents are most often studied in relation to paediatric obesity rather than their own. ${ }^{53}$ In one 
Table 4 Results of multilevel regression models of obesity (men; National Population Health Survey 1994-2010, N=3024)

\begin{tabular}{|c|c|c|c|c|c|c|}
\hline & Model 1 & & Model 2 & & Model 3 & \\
\hline Psychological distress & & & 0.97 & $0.93-1.01$ & 0.96 & $0.93-1.00$ \\
\hline \multicolumn{7}{|l|}{ Work } \\
\hline Skill utilisation & 1.01 & $0.96-1.06$ & & & 1.01 & $0.96-1.06$ \\
\hline Decision authority & 1.03 & $0.97-1.09$ & & & 1.03 & $0.97-1.10$ \\
\hline Psychological demands & 1.03 & $0.97-1.09$ & & & 1.03 & $0.97-1.09$ \\
\hline Physical demands & 0.95 & $0.88-1.03$ & & & 0.95 & $0.88-1.03$ \\
\hline Social support at work & 0.98 & $0.93-1.03$ & & & 0.98 & $0.93-1.03$ \\
\hline Job insecurity & 0.93 & $0.85-1.02$ & & & 0.93 & $0.85-1.02$ \\
\hline Work schedule (irregular) & 1.04 & $0.84-1.29$ & & & 1.04 & $0.85-1.29$ \\
\hline Working hours (total) & 1.00 & $1.00-1.01$ & & & 1.00 & $0.99-1.01$ \\
\hline \multicolumn{7}{|l|}{ Non-work } \\
\hline Marital status (couple) & $1.43^{\star *}$ & $1.10-1.86$ & & & $1.42^{\star \star}$ & $1.09-1.84$ \\
\hline Family income & 1.03 & $0.89-1.18$ & & & 1.03 & $0.89-1.18$ \\
\hline Child at home & 1.00 & $0.80-1.26$ & & & 1.00 & $0.80-1.25$ \\
\hline Couple-related strains & 0.91 & $0.78-1.05$ & & & 0.92 & $0.79-1.07$ \\
\hline Child-related strains & 1.17 & $1.00-1.37$ & & & $1.18^{*}$ & $1.01-1.38$ \\
\hline Social support outside work (high) & 0.94 & $0.66-1.34$ & & & 0.92 & $0.65-1.31$ \\
\hline \multicolumn{7}{|l|}{ Individual } \\
\hline Age & 0.99 & $0.98-1.00$ & 0.99 & $0.98-1.01$ & 0.99 & $0.97-1.00$ \\
\hline Level of education & 0.96 & $0.91-1.01$ & 0.97 & $0.93-1.02$ & 0.96 & $0.91-1.01$ \\
\hline Locus of control & 1.01 & $0.98-1.03$ & 1.01 & $0.98-1.03$ & 1.00 & $0.98-1.03$ \\
\hline Stressful childhood events & 1.07 & $0.93-1.23$ & 1.08 & $0.95-1.24$ & 1.08 & $0.94-1.23$ \\
\hline Hazardous alcohol consumption & 1.34 & $0.98-1.85$ & 1.37 & $0.97-1.95$ & 1.36 & $0.99-1.87$ \\
\hline Cigarettes & 0.99 & $0.83-1.18$ & 0.99 & $0.97-1.01$ & 0.99 & $0.97-1.01$ \\
\hline Physical activity & $0.99^{\star \star}$ & $0.99-0.998$ & $0.99^{\star *}$ & $0.99-0.998$ & $0.99^{\star \star}$ & $0.99-1.00$ \\
\hline Hypertension & $1.47^{\star}$ & $1.03-2.09$ & $1.44^{\star}$ & $1.02-2.03$ & $1.48^{\star}$ & $1.04-2.10$ \\
\hline Diabetes & 0.80 & $0.44-1.45$ & 0.83 & $0.45-1.55$ & 0.82 & $0.45-1.51$ \\
\hline Psychotropic drug use & 1.10 & $0.81-1.48$ & 1.12 & $0.83-1.53$ & 1.15 & $0.85-1.57$ \\
\hline \multicolumn{7}{|l|}{ Time } \\
\hline Cycle 3 & $4.81^{\star *}$ & $3.62-6.40$ & $4.73^{\star \star}$ & $3.58-6.24$ & $4.77^{\star \star}$ & $3.59-6.35$ \\
\hline Cycle 4 & $6.51^{\star *}$ & $4.67-9.07$ & $6.47^{\star *}$ & $4.70-8.89$ & $6.39^{\star \star}$ & 4.57-8.94 \\
\hline Cycle 5 & $7.50^{\star \star}$ & $5.25-10.70$ & $7.70^{\star \star}$ & $5.56-10.68$ & $7.41^{\star *}$ & $5.18-10.61$ \\
\hline Cycle 6 & $8.57^{\star \star}$ & $5.92-12.41$ & $8.88^{\star \star}$ & $6.30-12.50$ & $8.49^{\star *}$ & $5.86-12.30$ \\
\hline Cycle 7 & $9.30^{\star *}$ & $6.21-13.92$ & $9.59^{\star *}$ & $6.60-13.94$ & $9.21^{\star *}$ & $6.12-13.87$ \\
\hline Cycle 8 & $11.36^{\star *}$ & $7.50-17.21$ & $11.80^{* *}$ & $8.02-17.38$ & $11.33^{\star *}$ & $7.46-17.23$ \\
\hline \multicolumn{7}{|l|}{ Random part } \\
\hline$\sigma^{2}$ Individuals & $2.58^{\star \star}$ & $2.16-3.01$ & $3.20^{\star \star}$ & $2.43-3.97$ & $3.21^{\star *}$ & $2.47-3.95$ \\
\hline \multicolumn{7}{|l|}{ Goodness-of-fit } \\
\hline$\chi^{2}(\mathrm{df})$ & $591.18(30)$ & & 488.23 (17) & & $520.21(31)$ & \\
\hline
\end{tabular}

study exploring the role of parenting stress on obesity in parents as well as children enrolled in a paediatric weight management programme, Guilfoyle et $a l^{54}$ noted that $18 \%$ of parents reported clinically elevated levels of parenting stress, among which $66 \%$ were obese or morbidly obese. Having to take care of an obese child with special health needs might be a demanding task at hand (eg, emotional support of the child, monitor child adherence to health intervention), competing with resources (eg, time, knowledge, motivation, spousal support) parents must deploy to adopt and maintain healthier lifestyles for themselves. Given that our indicator of child-related strains expressed general (ie, presence of an unhappy child, serious concerns about the child) rather than specific strains (eg, presence of an obese child with special health needs), additional quantitative and qualitative insights are thus required to characterise how child-related strains associate with obesity among working parents. Nevertheless, this result gives further credence to mounting evidence emphasising the pivotal role of the quality of the family environment as a strong determinant not only for paediatric but also for adult obesity. ${ }^{55}$ As a rule, studies show that becoming a parent causes BMI to rise as new parents develop lifestyles that are more sedentary and involve less exercise. ${ }^{56}$ In addition, when we controlled for psychological distress, the child-related strains associate with increasing risks of becoming obese. As far as we know, our study is the first to bring the relationship between child-related strains and obesity to light among workers.

As for individual characteristics, first, the obesity risk over time is higher for men than women, which is not supportive of research that has reported increasing risks of obesity in women ${ }^{1324}$ but has failed to consider 
Table 5 Results of multilevel regression models of obesity (women; National Population Health Survey 1994-2010, N=2901)

\begin{tabular}{|c|c|c|c|c|c|c|}
\hline & Model 1 & & Model 2 & & Model 3 & \\
\hline Psychological distress & & & 0.98 & $0.95-1.01$ & 0.97 & $0.94-1.01$ \\
\hline \multicolumn{7}{|l|}{ Work } \\
\hline Skill utilisation & 0.97 & $0.93-1.02$ & & & 0.97 & $0.93-1.02$ \\
\hline Decision authority & $0.93^{\star}$ & $0.88-0.99$ & & & $0.93^{\star}$ & $0.88-0.99$ \\
\hline Psychological demands & 1.04 & $0.98-1.11$ & & & 1.05 & $0.98-1.11$ \\
\hline Physical demands & 1.00 & $0.91-1.10$ & & & 1.00 & $0.90-1.10$ \\
\hline Social support at work & 0.98 & $0.93-1.03$ & & & 0.98 & $0.93-1.03$ \\
\hline Job insecurity & 0.98 & $0.88-1.10$ & & & 0.98 & $0.88-1.09$ \\
\hline Work schedule (irregular) & 0.94 & $0.72-1.23$ & & & 0.94 & $0.72-1.24$ \\
\hline Working hours (total) & 1.00 & $0.99-1.01$ & & & 1.00 & $0.99-1.01$ \\
\hline \multicolumn{7}{|l|}{ Non-work } \\
\hline Marital status (couple) & 1.18 & $0.88-1.60$ & & & 1.17 & $0.87-1.59$ \\
\hline Family income & 0.97 & $0.84-1.11$ & & & 0.97 & $0.84-1.11$ \\
\hline Child at home & 1.02 & $0.79-1.32$ & & & 1.02 & $0.79-1.31$ \\
\hline Couple-related strains & 1.11 & $0.95-1.30$ & & & 1.12 & $0.95-1.32$ \\
\hline Child-related strains & 1.04 & $0.89-1.21$ & & & 1.04 & $0.89-1.21$ \\
\hline Social support outside work (high) & 0.84 & $0.57-1.22$ & & & 0.81 & $0.55-1.20$ \\
\hline \multicolumn{7}{|l|}{ Individual } \\
\hline Age & 1.01 & $0.99-1.03$ & 1.01 & $0.99-1.02$ & 1.01 & $0.99-1.02$ \\
\hline Level of education & 1.04 & $0.98-1.11$ & 1.03 & $0.97-1.10$ & 1.05 & $0.99-1.11$ \\
\hline Locus of control & 0.99 & $0.97-1.02$ & $0.97^{*}$ & $0.95-0.99$ & 0.99 & $0.96-1.01$ \\
\hline Stressful childhood events & 1.09 & $0.96-1.23$ & 0.90 & $0.80-1.02$ & 1.10 & $0.97-1.24$ \\
\hline Hazardous alcohol consumption & 0.67 & $0.44-1.02$ & 0.67 & $0.44-1.03$ & 0.67 & $0.43-1.02$ \\
\hline Cigarettes & 0.99 & $0.97-1.02$ & 0.99 & $0.97-1.02$ & 0.99 & $0.97-1.02$ \\
\hline Physical activities & $0.99^{\star \star}$ & $0.99-1.00$ & $0.99^{* *}$ & $0.99-1.00$ & $0.99^{\star \star}$ & $0.99-1.00$ \\
\hline Hypertension & $1.81^{\star}$ & $1.09-3.01$ & $1.78^{*}$ & $1.08-2.93$ & $1.81^{\star}$ & $1.09-3.01$ \\
\hline Diabetes & 0.81 & $0.21-3.09$ & 0.86 & $0.24-3.16$ & 0.81 & $0.21-3.12$ \\
\hline Psychotropic drug use & 1.21 & $0.91-1.60$ & 1.27 & $0.95-1.70$ & 1.25 & $0.93-1.66$ \\
\hline \multicolumn{7}{|l|}{ Time } \\
\hline Cycle 3 & $3.91^{\star *}$ & $2.78-5.49$ & $3.87^{\star \star}$ & $2.78-5.40$ & $3.86^{\star \star}$ & $2.75-5.42$ \\
\hline Cycle 4 & $5.33^{\star *}$ & $3.79-7.49$ & $5.12^{* *}$ & $3.67-7.15$ & $5.23^{\star \star}$ & $3.73-7.36$ \\
\hline Cycle 5 & $6.75^{\star \star}$ & $4.53-10.06$ & $6.50^{\star *}$ & $4.44-9.53$ & $6.63^{\star \star}$ & $4.45-9.87$ \\
\hline Cycle 6 & $8.49^{* *}$ & $5.59-12.87$ & $7.97^{\star \star}$ & $5.31-11.95$ & $8.45^{\star \star}$ & $5.56-12.80$ \\
\hline Cycle 7 & $11.19^{\star *}$ & $7.24-17.29$ & $10.55^{\star *}$ & $6.94-16.06$ & $11.11^{* *}$ & $7.19-17.16$ \\
\hline Cycle 8 & $12.51^{\star \star}$ & $7.85-19.96$ & $11.93^{\star *}$ & $7.58-18.78$ & $12.56^{\star \star}$ & $7.87-20.07$ \\
\hline \multicolumn{7}{|l|}{ Random part } \\
\hline$\sigma^{2}$ Individuals & $4.86^{\star \star}$ & $3.41-6.30$ & $4.85^{\star \star}$ & $3.38-6.31$ & $4.82^{\star \star}$ & $3.38-6.26$ \\
\hline \multicolumn{7}{|l|}{ Goodness-of-fit } \\
\hline$\chi^{2}(d f)$ & $486.37(30)$ & & $393.60(17)$ & & $496.50(31)$ & \\
\hline
\end{tabular}

jointly the contribution of work and non-work factors. Second, and consistent with a previous study, ${ }^{21}$ physical activity helps in reducing obesity risk for both men and women. Third, hypertension exposes men and women to approximately the same obesity risk. This result accorded with new research on the role of abdominal obesity in cardiovascular diseases and the link between obesity and hypertension. ${ }^{57}$ In a population-based study in Croatia, however, no difference between men and women regarding the role of hypertension was found. ${ }^{58}$ Fourth, psychotropic drug use had an overall impact on obesity risk. Although research has shown that on average men use psychotropic drugs less than women do, men also see physicians less often, which affects how many antidepressant prescriptions are written for them. ${ }^{59}$ Taken together, these dynamics differentiate men in non-negligible ways. Indeed, it turns out that weight gain is known to be one of the side effects of psychotropic drugs, ${ }^{60}$ as psychotropic medications tend to stimulate appetite. ${ }^{61}$

Finally, the results of this study show the expected mediation effect for psychological distress to be not statistically significant, because few work factors associated with obesity. Consequently, the association work factors have on obesity could not be mediated by psychological distress. Overall, psychological distress tended to decrease obesity risk and the association was not moderated by gender. Systematic reviews examining associations between mental health problems and obesity notably among community samples of adults shed additional light on our results. First, there might be specific pathways through which psychopathology becomes a risk 
factor for obesity, with risk-pattern associations being more consistently evidenced by studies measuring severe psychopathology such as depression, bipolar disorders, ${ }^{62}{ }^{63}$ compared to prepathological conditions such as psychological distress. ${ }^{64}{ }^{65}$ Severe psychopathology such as depression may more acutely trigger biological pathways pertaining to a dysregulation of the neuroendocrine system (eg, cortisol, insulin) associated with obesity. ${ }^{63}$ One might also speculate that obesity could be a concomitant of the medications that severe expressions of psychopathology often require. ${ }^{62}$ Hence, that psychological distress as a prepathological mental health condition acted as a protective factor in time for obesity in our study, in spite of the small magnitude of the effect observed, invites us to reconsider the dose-response association for mental health problems to negatively impact on obesity risk in working populations. Such hypothesis would be in line with findings from a recent meta-analysis $^{65}$ reporting less psychological distress among moderately obese individuals (class I with a BMI range between 30 and $34.99 \mathrm{~kg} / \mathrm{m}^{2}$ ) as opposed to their normal weight counterparts among a sample of crosssectional studies. Examination of gender differences further indicated that this association stood only for men, while obese women tended to experience more psychological distress than normal weight women. While we did not replicate such gender-based differences, our results add a novel outlook at causal patterns. Second, the specific temporal sequence between obesity and psychological distress examined might also explain the absence of association with obesity in our study. Systematic reviews also support emerging trends in the literature where the onset of mental health problems appears as a consequence of social isolation, stigma and discrimination experienced by obese individuals, which we did not assess in our study. ${ }^{66}$ Future efforts in research should aim at clarifying both the nature of the psychopathology and directionality linking mental health and obesity among representative samples of the working population.

This study has limitations. First, the BMI measure we used is derived from self-reported data, although it has been corrected to minimise gender response bias. ${ }^{36}$ Second, we did not control for high levels of exposure to physical and chemical risks (eg, dirt, humidity, low light, solvents, gas, irritating substances, heat, cold, mould, noise, vibration), although the literature seems to show that these factors lead to weight gain among men. ${ }^{23}$ Third, the measure we used for physical activity was based solely on the duration that respondents assigned to it for the 3 months preceding the survey. It does not measure the intensity of physical effort, nor does it yield information about periods when physical activity slackened. Physical activity is indeed a good method for losing weight, but once weight is lost it is often regained when exercise levels drop off. ${ }^{67}$ Fourth, as many variables were simultaneously regressed, there was a risk of overadjustment. However, the sample size was large enough to provide a strong adjustment of variables in the models. Fifth, the strength of associations found in this study is relatively low, which is an indication that the possible causal mechanisms need to be further studied. Last, we cannot rule out the possibility of a common method variance bias, because all measurements were based on one source. This may not have influenced the relationship between independent variable and obesity risk, because the sample was selected as free of obesity at cycle 1 of the NPHS.

\section{CONCLUSION}

The results of this study suggest that good mental health (ie, low psychological distress), non-work factors (ie, living in couple, child-related strains) and individual characteristics (ie, physical inactivity, hypertension and psychotropic medication) are predictive factors of obesity for both men and women, while work factors (ie, low decision authority) only contribute to additionally predict women's obesity risk. Contrary to what we anticipated, psychological distress did not mediate the relationship between work factors and obesity risk. Combined with our past efforts in occupational mental health based on the longitudinal cohort of the NPHS, ${ }^{44} 68$ this study is an important first step in understanding the complex interplay between obesity and psychological distress as concomitant health outcomes of concern among Canadian workers.

\section{Author affiliations}

${ }^{1}$ School of Industrial Relations, University of Montreal, Montreal, Quebec, Canada

${ }^{2}$ University of Montreal Research Institute in Public Health, Montreal, Quebec, Canada

Twitter Follow Nancy Beauregard at @UdeM_NancyB and Marie-Eve Blanc at @ertsm

Acknowledgements The authors would like to acknowledge the Quebec Interuniversity Centre for Social Statistics in Montreal for permitting them to access Statistics Canada data. The analysis presented in this paper was conducted at the Quebec Interuniversity Centre for Social Statistics which is part of the Canadian Research Data Centre Network (CRDCN). The services and activities provided by the QICSS are made possible by the financial or in-kind support of the SSHRC, the ClHR, the CFI, Statistics Canada, the FRQSC and the Quebec universities. Their special thanks are due to Nathalie Dumas for her expertise and advice on the subject of obesity.

Contributors $A M$ and NB were responsible for the conception of this paper. $A M, N B$ and M-EB analysed the data and M-EB drafted the manuscript. All authors interpreted the data, participated in critical revisions of the paper and approved the final submitted version.

Funding This research was financed by the University of Montreal Research Institute in Public Health and the Canadian Institutes of Health Research (grant 201106DGE-256351-KDE-CFCA-114863).

\section{Competing interests None.}

Ethics approval This study was approved by the Research Ethic Board of University of Montreal's Faculty of Arts and Science (certificate number \# CERFAS-2012-13-014)

Provenance and peer review Not commissioned; externally peer reviewed.

Data sharing statement No additional data are available. 
Open Access This is an Open Access article distributed in accordance with the Creative Commons Attribution Non Commercial (CC BY-NC 4.0) license, which permits others to distribute, remix, adapt, build upon this work noncommercially, and license their derivative works on different terms, provided the original work is properly cited and the use is non-commercial. See: http:// creativecommons.org/licenses/by-nc/4.0/

\section{REFERENCES}

1. Paquot N, De Flines J, Rorive M. [Obesity: a model of complex interactions between genetics and environment]. Rev Med Liege 2012;67:332-6.

2. Barry D, Petry N. Gender differences in associations between stressful life events and body mass index. Prev Med 2008;47:498-503.

3. Andersen I, Burr H, Kristensen TS, et al. Do factors in the psychosocial work environment mediate the effect of socioeconomic position on the risk of myocardial infarction? Study from the Copenhagen Centre for Prospective Population Studies. Occup Environ Med 2004;61(11):886-92.

4. Overgaard D, Gyntelberg F, Heitman BL. Psychological workload and body weight: is there an association? A review of the literature. Occup Med (Lond) 2004;54:35-41.

5. Wardle J, Chida Y, Gibson EL, et al. Stress and adiposity: a meta-analysis of longitudinal studies. Obesity 2011;19:771-8.

6. Siegrist J, Rodel A. Work stress and health risk behavior. Scand $J$ Work Environ Health 2006;32:473-81.

7. Solovieva S, Lallukka T, Virtanen M, et al. Psychosocial factors at work, long work hours, and obesity: a systematic review. Scand J Work Environ Health 2013;39:241-58.

8. Karasek RA. Job demands, job decision latittude, and mental strain: implications for job redesign. Adm Sci Q 1979;24:285-308.

9. Karasek RA, Theorell T. Healthy work. Stress, productivity, and the reconstruction of working life. New York: Basic Book, 1990.

10. Siegrist J. Adverse health effects of high effort-low reward conditions at work. J Occup Health Psychol 1996;1:27-43.

11. Kivimaki M, Head J, Ferrie JE, et al. Work stress, weight gain and weight loss: evidence for bidirectional effects of job strain on body mass index in the Whitehall II study. Int J Obes (Lond) 2006;30(6):982-7.

12. Nyberg ST, Heikkila K, Fransson El, et al. Job strain in relation to body mass index: pooled analysis of 160000 adults from 13 cohort studies. J Intern Med 2012;272(1):65-73.

13. Sund ER, Jones A, Midthjell K. Individual, family, and area predictors of BMI and BMl change in an adult Norwegian population: findings from the HUNT study. Soc Sci Med 2010;70:1194-202.

14. Lallukka T, Sarlio-Lahteenkorva S, Kaila-Kangas L, et al. Working conditions and weight gain: a 28-year follow-up study of industrial employees. Eur J Epidemiol 2008;23:303-10.

15. Overgaard D, Gamborg M, Gyntelberg F, et al. Psychological workload is associated with weight gain between 1993 and 1999: analyses based on the Danish Nurse Cohort Study. Int J Obes Relat Metab Disord 2004;28:1072-81.

16. Hannerz H, Albertsen K, Nielsen ML, et al. Occupational factors and 5 -year weight change among men in a Danish National Cohort. Health Psychol 2004;23:283-8.

17. Berset $\mathrm{M}$, Semmer NK, Elfering $A$, et al. Does stress at work make you gain weight? A two-year longitudinal study. Scand J Work Environ Health 2011;37:45-53.

18. Kivimaki $\mathrm{M}$, Leino-Arjas $\mathrm{P}$, Luukkonen $\mathrm{R}$, et al. Work stress and risk of cardiovascular mortality: prospective cohort study of industrial employees. BMJ 2002;325:857.

19. Block JP, He Y, Zaslavsky AM, et al. Psychosocial stress and change in weight among US adults. Am J Epidemiol 2009;170:181-92.

20. Brunner EJ, Chandola T, Marmot MG. Prospective effect of job strain on general and central obesity in the Whitehall II study. Am J Epidemiol 2007;165:828-37.

21. Eek F, Ostergren PO. Factors associated with BMI change over five years in a Swedish adult population. Results from the Scania public health cohort study. Scand J Public Health 2009;37:532-44.

22. Lallukka T, Laaksonen M, Martikainen $\mathrm{P}$, et al. Psychosocial working conditions and weight gain among employees. Int $J$ Obes (Lond) 2005:29:909-15.

23. Roos E, Lallukka T, Rahkonen O, et al. Working conditions and major weight gain-a prospective cohort study. Arch Environ Occup Health 2013;68:166-72.

24. Magee CA, Caputi P, Stefanic N, et al. Occupational factors associated with 4-year weight gain in Australian adults. J Occup Environ Med 2010;52:977-81
25. Iversen LB, Strandberg-Larsen K, Prescott E, et al. Psychosocial risk factors, weight changes and risk of obesity: the Copenhagen City Heart Study. Eur J Epidemiol 2012;27:119-30.

26. Beauregard N, Marchand A, Blanc ME. What do we know about the non-work determinants of workers' mental health? A systematic review of longitudinal studies. BMC Public Health 2011;11:439.

27. Dugravot A, Sabia S, Stringhini S, et al. Do socioeconomic factors shape weight and obesity trajectories over the transition from midlife to old age? Results from the French GAZEL cohort study. Am J Clin Nutr 2010;92:16-23.

28. McLaren L. Socioeconomic status and obesity. Epidemiol Rev 2007;29:29-48.

29. $\mathrm{Ng}$ IS, Cheung KC, Chou KL. Correlates of eating disorder in middle-aged and older adults: evidence from 2007 British National Psychiatric Morbidity Survey. J Aging Health 2013;25:1106-20.

30. Sutin AR, Ferrucci L, Zonderman AB, et al. Personality and obesity across the adult life span. J Pers Soc Psychol 2011;101:579-92.

31. Toren K, Schioler L, Giang WK, et al. A longitudinal general population-based study of job strain and risk for coronary heart disease and stroke in Swedish men. BMJ Open 2014;4:e004355.

32. Kivimaki M, Lawlor DA, Singh-Manoux A, et al. Common mental disorder and obesity: insight from four repeat measures over 19 years: prospective Whitehall II cohort study. BMJ 2009;339:b3765.

33. Nishitani N, Sakakibara H. Relationship of BMl increase to eating behavior and job stress in a 2-year cohort study of non-obese male Japanese workers. Obes Res Clin Pract 2007;1:179-85.

34. Marchand A, Durand P, Haines V III, et al. The multilevel determinants of workers' mental health: results from the SALVEO study. Soc Psychiatry Psychiatr Epidemiol 2015;50:445-59.

35. Marchand A, Durand $P$, Demers A. Un modèle multiniveaux des déterminants de la santé mentale dans la main d'oeuvre. Rev Can Can J Commun Ment Health 2006;25:11-30.

36. Connor Gorber S, Shields M, Tremblay MS, et al. The feasibility of establishing correction factors to adjust self-reported estimates of obesity. Health Rep 2008;19:71-82.

37. Kessler RC, Andrews G, Colpe LJ, et al. Short screening scales to monitor population prevalences and trends in non-specific psychological distress. Psychol Med 2002;32(6):959-76.

38. World Health Organization. Composite international diagnostic interview. Version 1.0. Geneva: World Health Organization, 1990.

39. Wheaton $B$. The role of sociology in the study of mental health...and the role of mental health in the study of sociology. J Health Soc Behav 2001;42:221-34.

40. Dohrenwend BP, Shrout PE, Egri G, et al. Nonspecific psychological distress and other dimensions of psychopathology. Arch Gen Psychiatry 1980;37:1229-36.

41. Karasek R, Gordon G, Pietrokovsky C, et al. Job content questionnaire: questionnaire and users' guide. Lowell: University of Massachusetts, 1985

42. Wheaton B. Sampling the stress universe. In: Avison WR, Gotlib IH, eds. Stress and mental health contemporary issues and prospects for the future. New York: Plenum Press, 1994:77-114

43. Pearlin LI, Schooler C. The structure of coping. J Health Soc Behav 1978;19:2-21.

44. Marchand A, Demers A, Durand P. Do occupation and work conditions really matter? A longitudinal analysis of psychological distress experiences among Canadian workers. Sociol Health IIIn 2005;27:602-27.

45. Goldstein H. Multilevel statistical models. London; New York: Edward Arnold; Halstead Press, 1995.

46. Baron RM, Kenny DA. The moderator-mediator variable distinction in social psychological research: conceptual, strategic, and statistical considerations. J Pers Soc Psychol 1986;51:1173-82.

47. Altman DG, Bland JM. Interaction revisited: the difference between two estimates. BMJ 2003;326:219.

48. Black SE, Juhn $\mathrm{CH}$. The rise of female professionals: are women responding to skill demand? Am Econ Rev 2000;90:450-5.

49. National Obesity Observatory. Adult weight. Secondary adult weight, 2011. http://www.noo.org.uk/uploads/doc/vid_11515_Adult_Weight_ Data_Briefing.pdf

50. Joensuu M, Kivimaki M, Pentti J, et al. Components of job control and mortality: the Finnish Public Sector Study. Occup Environ Med 2014;71:536-42.

51. Brunner EJ, Marmot MG, Nanchahal K, et al. Social inequality in coronary risk: central obesity and the metabolic syndrome. Evidence from the Whitehall II study. Diabetologia 1997;40(11):1341-9.

52. Averett SL, Sikora A, Argys LM. For better or worse: relationship status and body mass index. Econ Hum Biol 2008;6:330-49. 
53. Gundersen C, Mahatmya D, Garasky S, et al. Linking psychosocial stressors and childhood obesity. Obes Rev 2011;12: e54-63.

54. Guilfoyle SM, Zeller MH, Modi AC. Parenting stress impacts obesity-specific health-related quality of life in a pediatric obesity treatment-seeking sample. J Dev Behav Pediatr 2010;31:17-25.

55. Gruber KJ, Haldeman LA. Using the family to combat childhood and adult obesity. Prev Chronic Dis 2009;6:A106.

56. Laroche HH, Wallace RB, Snetselaar L, et al. Weight gain among men and women who have a child enter their home. J Acad Nutr Diet 2013;113:1504-10.

57. Ostchega Y, Hughes JP, Terry A, et al. Abdominal obesity, body mass index, and hypertension in US adults: NHANES 2007-2010. Am J Hypertens 2012;25:1271-8.

58. Uhernik Al, Milanovic SM. Anthropometric indices of obesity and hypertension in different age and gender groups of Croatian population. Coll Antropol 2009;33(Suppl 1):75-80.

59. Wang Y, Hunt K, Nazareth I, et al. Do men consult less than women? An analysis of routinely collected UK general practice data. BMJ Open 2013;3:e003320.

60. Smits JA, Rosenfield D, Mather AA, et al. Psychotropic medication use mediates the relationship between mood and anxiety disorders and obesity: findings from a nationally representative sample. J Psychiatr Res 2010;44:1010-16.
61. Ruetsch O, Viala A, Bardou H, et al. [Psychotropic drugs induced weight gain: a review of the literature concerning epidemiological data, mechanisms and management]. L'Encephale 2005;31 (4 Pt 1):507-16.

62. McElroy SL, Kotwal R, Malhotra S, et al. Are mood disorders and obesity related? A review for the mental health professional. $J$ Clin Psychiatry 2004;65:634-51, quiz 730.

63. Luppino FS, de Wit LM, Bouvy PF, et al. Overweight, obesity, and depression a systematic review and meta-analysis of longitudinal studies. Arch Gen Psychiatry 2010;67(3):220-9.

64. Fabricatore AN, Wadden TA. Psychological aspects of obesity. Clin Dermatol 2004;22:332-7.

65. Magallares A, Pais-Ribeiro JL. Mental health and obesity: a meta-analysis. Appl Res Qual Life 2014;9:295-308.

66. Gariepy G, Nitka D, Schmitz N. The association between obesity and anxiety disorders in the population: a systematic review and meta-analysis. Int J Obes (Lond) 2010;34:407-19.

67. Wilmore $\mathrm{JH}$. Weight gain, weight loss, and weight control: what is the role of physical activity? Nutrition 1997;13:820-2.

68. Marchand A, Demers A, Durand P. Social structures, agent personality and workers' mental health: a longitudinal analysis of the specific role of occupation and of workplace constraints-resources on psychological distress in the Canadian workforce. Hum Relat 2006;59:875-901. 